\title{
Estereótipos e subjetividade na argumentação em sentenças judiciais
}

\author{
Stereotypes and subjectivity in court sentences argumentation \\ Ana Lúcia Tinoco CABRAL* \\ Universidade Cruzeiro do Sul (UNICSUL) \\ Antonio Marcos Conceição \\ Universidade Cruzeiro do Sul (UNICSUL)
}

\begin{abstract}
RESUMO: As ações judiciais têm por função dirimir conflitos de interesse; cabe ao juiz determinar aquele que poderá ser considerado o detentor do direito, o que ele faz na sentença judicial. Ao longo do tempo, consolidou-se na sociedade a ideia de que os magistrados exercem seu papel de julgador de forma neutra e imparcial. $\mathrm{O}$ artigo põe em questão essa ideia e, visando a observar como o juiz marca suas crenças ao proferir as sentenças, apresenta, a título de exemplificação, a análise de uma sentença judicial, na qual verifica a presença de estereótipos e como eles manifestam a subjetividade na argumentação desenvolvida para fundamentar as decisões finais e justificar a sentença proferida. A base teórica para o desenvolvimento do texto constitui o estudo dos estereótipos (AMOSSY; PIERROT, [1997] 2007), aliado à questão das marcas de subjetividade na linguagem (KERBRAT-ORECCHIONI, [1980] 1997).
\end{abstract}

PALAVRAS-CHAVE: Discurso jurídico. Argumentação. Estereótipos. Subjetividade da linguagem. Sentenças judiciais.

ABSTRACT: Court Sentences have as function to resolve conflicts of interest; the judge shall decide who will be considered the rights holder, determined by him, through a court sentence. Throughout time, the idea that magistrates perform their judgmental role in a neutral and impartial way has been consolidated within society. The article calls into question this idea and, aiming at observing how judges mark their beliefs when delivering the judgment, it presents, by way of example, a court sentence analysis, in which it observes the presence of stereotypes and how subjectivity is conveyed by them through arguments adduced to base final decisions and to justify the judgment. The theoretical basis for the text development constitutes the stereotype study (Amossy \& Pierrot, [1997] 2007), along with the language subjectivity marks issue (Kerbrat-Orecchioni, [1980] 1997).

KEYWORDS: Legal discourse. Argumentation. Stereotypes. Language subjectivity. Court sentences.

\section{Introdução}

A sociedade preza pela convivência pacífica; com efeito, os cidadãos normalmente exercem seus direitos e gozam de seus bens em paz, mas há situações em que conflitos ocorrem. Podemos assim afirmar que a convivência entre os indivíduos produz três tipos de processos sociais: a cooperação, a competição e o conflito. A sociedade regula e regulamenta tais processos por meio das normas de direito,

* Professora Titular - Universidade Cruzeiro do Sul - Doutora em Lingua Portuguesa (PUCSP), altinococabral@gmail.com

**Instituto Federal de Educação Ciência e Tecnologia de São Paulo (IFSP); Mestre em Linguística pela Universidade Cruzeiro do Sul, markonpi@gmail.com 
essenciais para que os seres humanos possam coexistir e desenvolver as suas atividades de forma organizada.

Evidentemente, há muitas situações em que ocorrem choques de interesses, nas quais o indivíduo vê sua vontade ameaçada e até violada pela vontade do outro. A complexidade das relações nas sociedades modernas tornou a ocorrência de conflitos mais frequente, o que provocou um aumento na busca de solução para esses conflitos. É preciso lembrar com Cabral (2014, p. 59) que “o Estado não permite ao particular fazer justiça por suas próprias mãos, é direito do indivíduo convocar o Estado a fazer atuar a vontade da lei para atender essa pretensão". Surgem aí as ações judiciais, que têm por função dirimir conflitos de interesse. Nesse contexto, conforme lembra Cabral (2014, p.60), "a decisão do juiz determinará aquele que poderá ser considerado o detentor do direito".

Diante desse quadro, o Poder Judiciário, representado pelos magistrados, é visto pela sociedade como um símbolo da solução de seus problemas, uma vez que aquelas pretensões, seja de reparação dos danos sofridos, seja de imposição do cumprimento de alguma obrigação, ou, ainda, de punição dos criminosos, dependem das decisões proferidas pelos juízes.

Com efeito, ao longo do tempo consolidou-se na sociedade a ideia de que os magistrados agem sempre de forma neutra e imparcial, exercendo seu papel de julgadores com base na lógica racional, apoiados na lei, na busca da solução mais justa para a aplicação da justiça. Questionamos essa ideia; estamos convencidos que as decisões judiciais são guiadas, entre outros, pelas crenças dos juízes. Uma pergunta orienta nossas reflexões: Como o juiz, na sua atividade jurisdicional, ao proferir as sentenças, marca suas crenças?

A fim de responder a nossa pergunta, e tendo como texto de análise, a título de exemplificação, um acórdão proferido por uma câmara civil do Tribunal de Justiça do Estado do Rio de Janeiro em um recurso de apelação interposto contra a sentença de primeira instância, este trabalho busca investigar a presença de estereótipos em decisões judiciais. Observamos especificamente a argumentação desenvolvida para fundamentar as decisões finais e justificar a sentença proferida. Para tanto, constitui base teórica para o desenvolvimento deste texto o estudo dos estereótipos, principalmente os fundamentos postos por Amossy e Pierrot ([1997] 2007), que procuramos aliar à 
questão das marcas subjetividade na linguagem, tal como postula Kerbrat-Orecchioni ([1980] 1997), visto que estas refletem uma tomada de posição do locutor frente aos conteúdos enunciados (KERBRAT-ORECCHIONI, [1980] 1997; CABRAL, 2011).

A fim de cumprir o objetivo proposto, o trabalho organiza-se em três partes, além desta introdução e das considerações finais. Na primeira apresentamos alguns conceitos relativos às sentenças judiciais, situando o papel do juiz; na segunda, desenvolvemos brevemente os conceitos teóricos que darão suporte às nossas análises; na terceira, contextualizamos o texto analisado e expomos as análises.

\section{A Sentença e o juiz}

Conforme lembra Cabral (2014, p.59), o indivíduo, não tendo permissão para fazer justiça com as próprias mãos, busca o Estado para "fazer atuar a vontade da lei". O Poder Judiciário é o órgão investido de competência para apreciar o caso concreto que lhe for apresentado. Isso quer dizer que o Estado tem de ser invocado para agir na resolução de conflitos entre cidadãos. O juiz é o representante do Poder Judiciário e, portanto, aquele a quem caberá prover a tutela jurisdicional para pôr fim ao conflito, por meio do discurso decisório, ou seja, a sentença. É importante deixar claro, entretanto, que, conforme Cintra, Grinover e Dinamarco (2012), essa tutela nem sempre significa dar ao autor o que ele pede, porque a solução da lide pode não ser o que pretendia aquele que busca o Poder Judiciário.

Quando o Estado exerce a jurisdição, dá a cada um o que entende ser o direito, o que se concretiza, entre outros, pela sentença, conforme o Código de Processo Civil de 2015 (BRASIL, 2015, p.63), que estabelece em seu artigo 203: "os pronunciamentos do juiz consistirão em sentenças, decisões interlocutórias e despachos". O parágrafo $1^{\circ}$, do mesmo artigo 203 do Código de Processo Civil, expõe que a "sentença é o pronunciamento por meio do qual o juiz, com fundamento nos artigos 485 e 487, põe fim à fase cognitiva do procedimento comum, bem como extingue a execução" (BRASIL, 2015, p. 63). Quando a decisão judicial equivalente à sentença é proferida pelos tribunais, denomina-se Acórdão, que é definido pelo Código de Processo Civil em seu artigo 204: “acórdão é o julgamento colegiado proferido pelos tribunais" (BRASIL, 2015, p. 64). 
A estrutura do gênero sentença judicial no âmbito cível é estabelecida pela norma e dela não pode distanciar-se sob pena de nulidade. São elementos essenciais da sentença o relatório, os fundamentos e o dispositivo, conforme previsto no artigo 489 do Código de Processo Civil, constituindo condições intrínsecas de sua validade, de acordo com Theodoro Júnior (2007).

De acordo com o definido pela norma processual, por conseguinte, a primeira parte de uma sentença é o relatório, que consiste em um resumo do processo em que são nomeadas as partes, indicando também quais são os fundamentos do pedido e da defesa, e relatando brevemente os ocorridos no desenvolver do processo. Tal procedimento tem, entre as suas finalidades, a de demonstrar que o Juiz teve contato com a causa e a conhece adequadamente.

$\mathrm{Na}$ segunda parte da sentença, denominada fundamentos, o juiz deve indicar os motivos que formaram a sua convicção e que serviram de base para a sentença; os fundamentos decorrem do relatório e evidenciam a motivação da sentença, expondo como o caso concreto em litígio se enquadra nas normas legais aplicáveis que conduzirão à decisão.

A terceira e última parte da sentença, cujo nome é dispositivo, é a decisão da causa. No dispositivo, conforme lição de Theodoro Júnior (2007), o juiz poderá, conforme o caso, anular o processo, declarar sua extinção, julgar o autor carecedor da ação (ilegitimidade ad causam), ou julgar o pedido procedente ou improcedente.

Conforme entendimento de alguns juristas, como Cintra, Grinover e Dinamarco (2012), os juízes devem ter uma participação ativa no processo, pois é necessário fazer "justiça". Esses autores defendem que é dever do Juiz ter compromisso com a justiça. Desse ponto de vista, o juiz não deve apenas participar adequadamente das atividades processuais, mas também buscar, oferecer às partes a solução que realmente realize o objetivo de fazer justiça. A esse respeito, Dinamarco (2013, p.63) afirma que o processo é uma técnica "que deve ser informada pelos objetivos e ideologias revelados na ciência processual e levada a efeito com vista à efetivação do valor do justo".

Esse entendimento nos remete ao fato de que o direito é fruto de uma cultura e o processo é um dos meios pelo qual essa cultura se revela; nesse contexto, o processo é visto como um instrumento para a realização daquilo que a sociedade entende ser justo, 
dos direitos existentes na sociedade; estes, por sua vez, emergem dos valores que a alicerçam. Com efeito, os dizeres de Dinamarco (2013) corroboram esse entendimento:

\begin{abstract}
O juiz que vai aos princípios gerais e constitucionais ou considera as grandes premissas éticas da sociedade ao julgar, cumpre apenas um tradicional mandamento da própria ordem jurídica (os fins sociais da lei, art. $5^{\circ}$ LICC) e comporta-se como autêntico canal de comunicação entre os valores da sociedade em que vive e os casos concretos que julga. (DINAMARCO, 2013 p. 64)
\end{abstract}

Podemos assim compreender que o processo como um todo, e a sentença, especificamente, ultrapassa a sua característica de instrumentalidade técnica; trata-se de um instrumento técnico para realizar o direito material normatizado, mas envolve, sem dúvida, valores e crenças construídos na sociedade, implicando um caráter subjetivo e humanístico.

São sujeitos da relação jurídica processual o autor, o réu e o Estado-juiz. O autor e o réu postulam direitos e buscam a tutela jurisdicional. São, conforme Cabral (2016, p. 56), “os sujeitos parciais do processo: o autor age pedindo a prestação jurisdicional do Estado contra o réu, que resiste". O juiz, por sua vez, representando o Estado, em cumprimento do seu objetivo de alcançar o bem comum, tem o dever de prestar a tutela pretendida. Na condição de órgão do Estado, é esperado do juiz que atue como sujeito imparcial no processo e se coloque acima e entre as partes (CABRAL, 2007), atendendo ao princípio da imparcialidade; ele tem, portanto, o dever de agir com imparcialidade na apreciação das causas que lhes foram submetidas para solução.

Com o intuito de levar o juiz a exercer da melhor forma suas funções, a norma lhe atribui determinados poderes a serem exercidos; são poderes administrativos ou de polícia e também poderes jurisdicionais que se desenvolvem no curso da ação, dizendo respeito tanto ao desenvolvimento do processo, por meio dos atos ordinatórios, quanto à formação de seu convencimento, além daqueles relativos aos atos decisórios. Somente o juiz tem o poder de decisão no processo. Mas, para além de poderes, o juiz tem também deveres: o dever de decidir com base em fundamentos e o dever de obedecer às normas legais processuais e, principalmente, o dever de imparcialidade, isto é, ele não pode ser parte no processo e deve manter a desejável neutralidade em seu julgamento. Essa neutralidade deve, evidentemente, se fazer presente também nos textos de seus pronunciamentos. 
Depois de apresentadas as alegações das partes e cumpridas as diversas fases processuais previstas pela norma reguladora, compete ao Juiz proferir a sua decisão. Ao fazê-lo, o juiz deve observar os princípios e as normas legais, entre os quais, o princípio da persuasão racional do juiz, que garante ao juiz a possibilidade de formar livremente a sua convicção e se situa entre o sistema de prova legal e o do julgamento secundum conscientiam.

A doutrina do direito processual, entretanto, não estabelece com clareza que deve ser observado o princípio da persuasão racional do juiz. O princípio da prova legal vigorava no antigo processo germânico que atribuía aos elementos de prova um valor inalterável e prefixado. Vigorava, também, na Europa, no direito romano-canônico e no direito comum; de acordo com esse princípio, não competia ao juiz apreciar o caso, mas tão somente agir em relação à atribuição da prova, invocando a Deus (CINTRA, GRINOVER; DINAMARCO, 2012).

Numa visão contemporânea, por sua vez, o princípio secundum conscientizam indica que os julgadores sigam tão somente os ditames de sua consciência; desse ponto de vista, eles não estão submetidos a nenhuma obrigação de obedecer a qualquer regra externa para tomar uma decisão, o que vale é sua consciência. Cabe destacar que, pelo princípio da persuasão racional, o juiz não está desvinculado da prova e dos demais elementos que foram produzidos no desenrolar do processo; ele é, no entanto, livre para apreciar os fatos e o direito segundo os seus critérios subjetivos. O ordenamento jurídico impõe, entretanto, que todos os julgamentos e decisões sejam motivados, conforme consta expressamente no artigo 93, inciso IX da Constituição Federal (BRASIL, 1988).

Com efeito, ao produzir a sentença e julgar a causa, o juiz deve fazê-lo com base nos fatos alegados e provados pelas partes; não lhe compete sair em busca de provas que as partes não produziram. Cabe destacar, entretanto, que os poderes do Juiz aumentaram consideravelmente em relação às épocas pretéritas, quando ele exercia mais o papel de expectador do processo; nessa época, competia exclusivamente às partes a produção de provas e, basicamente, o estabelecimento dos rumos do processo; ao juiz, conforme já ressaltamos anteriormente neste trabalho, restava acatar ou não as provas produzidas e o rumos propostos. 
Atualmente, é o juiz quem promove o impulso do andamento processual, depois de acionado o Estado para prestar a jurisdição. Ele exerce, ainda, o papel de diretor material do processo e pode também determinar a realização de provas. O Juiz não é obrigado a julgar senão de acordo com o que entende ser correto, mesmo diante das restrições à expressão de seus posicionamentos subjetivos impostas pelas fórmulas previstas para o gênero decisão judicial.

\section{Argumentação e estereótipos}

Conforme Amossy e Pierrot ([1997] 2007), a noção de estereótipo chamou a atenção pelo estudo das "imagens na nossa cabeça". Com efeito, o conceito de estereótipos está ligado às imagens que construímos de nós mesmos e dos outros. Evidentemente, essa imagem tem muito a ver com o pertencimento, ou não, a determinada categoria de seres e a determinados grupos sociais. Assim, seguindo os exemplos apresentados pelos autores citados, podemos atribuir a um indivíduo o rótulo de advogado, de operário ou intelectual. Cada um desses rótulos permite ativar em nossa mente uma série de peculiaridades que normalmente associamos aos seres pertencentes a esses grupos. Trata-se de representações coletivas que, sem dúvida, exercem impacto na forma como encaramos as pessoas, como interagimos com elas, como as julgamos, enfim. É por isso que, para Al Kajousli (2007), os estereótipos são um verdadeiro instrumento para observar a língua e a sociedade. A afirmação desse autor nos remete à questão de como marcamos, por meio das escolhas linguísticas, nossos posicionamentos e nos remete a Kerbrat-Orecchioni ([1980] 1997), para quem toda unidade lexical é, em alguma medida, subjetiva.

O termo estereótipo tem sua origem no contexto da tipografia, isto é, ligado às placas estereotipadas que se usavam no processo tipográfico. A partir do século XX, segundo Amossy e Pierrot ([1997] 2007), a palavra, por analogia, passou a representar uma ideia de rigidez e imutabilidade, sendo aplicada com esse sentido no campo das ideias e da língua. Por analogia à rigidez da placa que mantem inalterado o que se deseja reproduzir na tipografia, o estereótipo diz respeito a representações cristalizadas num determinada sociedade. São esquemas culturais fundidos na história de determinada comunidade por meio dos quais as indivíduos avaliam a realidade que os cerca e, com base nesses julgamentos, tomam sua decisões. 
Considerando o estatuto social dos estereótipos, podemos afirmar que eles constituem ideias recebidas ao longo da formação do indivíduo, construindo sua opinião partilhada com o grupo ao qual pertence. Essas representações são fundamentais para compreendermos o mundo que nos cerca, sem o que, segundo Amossy e Pierrot ([1997] 2007), as pessoas não seriam capazes de compreender o real, categorizá-lo, ou nele atuar, por sentirem-se perdidas, tendo que refazer constantemente os conceitos sobre as coisas, tornando impossível o processo de compreensão do mundo em virtude do tempo que demandaria. Por esse motivo, o indivíduo busca sempre as características conhecidas cristalizadas em sua mente para compreender a realidade que o cerca. Mesmo que o estereótipo esquematize e categorize os seres, conduzindo a simplificações e generalizações muitas vezes excessivas, eles são necessários para que se estabeleçam relações a modelos preexistentes e para que se possa compreender o mundo, realizar previsões e regular as próprias condutas.

Diversas disciplinas usam o conceito de estereótipo, especialmente associandoo a um processo de generalização vinculado ao exercício do pensamento. Em linguística, de acordo com Amossy e Pierrot ([1997] 2007), a sua introdução se deu na década de 70 e, desde então, é empregado em estudos a respeito dos sentidos e significados na linguagem. Podemos associá-lo também aos conceitos de pré-construído, ou preconceitos e de senso comum. Para Charaudeau (2007), a questão do estereótipo diz respeito à relação da linguagem com a construção do real.

Amossy e Pierrot ([1997] 2007) definem o estereótipo como uma ideia convencional, associada a uma palavra ou expressão, em determinada cultura. Desde o seu surgimento como conceito, o estereótipo tem uma avaliação pejorativa que lhe é associada. Isso se deve, segundo esses mesmos autores, ao enfoque que lhe foi dado em particular pela psicologia social de origem norte-americana, segundo a qual o estereótipo responde a um processo de categorização e generalização pelo qual se recorta o real, o que pode provocar uma visão esquemática e deformada do outro. É importante ter claro, no entanto, que os estereótipos constituem crenças sobre as classes de indivíduos, de grupos ou objetos que se originam de valores preconcebidos e que constituem hipóteses não confirmadas por provas, mas que, ainda assim, são total ou parcialmente consideradas como fatos concretos, verdades. 
Embora considerados vilões, os estereótipos têm um papel importante nas relações sociais, pois, conforme destaca Rheault (2007), eles dizem respeito ao que é socialmente admitido; isto é, os estereótipos correspondem àquilo que os membros de uma comunidade aceitam como evidente, sem questionar. Daí a sua eficácia nos contextos em que a argumentação é importante, como, por exemplo, as demandas judiciais. De acordo com Amossy e Pierrot ([1997] 2007), a estereotipia é necessária ao bom funcionamento argumentativo, estando na base de todo discurso de visada persuasiva.

Cabe ainda lembrar com Amossy e Pierrot ([1997] 2007) que, devido ao seu caráter cultural, a que estão intrinsecamente ligados, sendo, como mencionam os autores, obrigatórios numa cultura, os estereótipos podem transformar-se, evoluir com as crenças. Desse ponto de vista, o estereótipo não constitui uma entidade pejorativa, como costuma ser avaliado pelo senso comum; ao contrário, é sobretudo o reflexo de uma sociedade em determinada época, uma vez que ele tem a ver com as convenções sociais.

Boyer (2007), por sua vez, ressaltando o caráter caricatural do estereótipo, ressalta que o seu conteúdo representacional tende à desvalorização do objeto a ele associado, embora existam estereótipos positivos. A observação do autor nos permite afirmar que o estereótipo traz sempre uma avaliação daquele que o utiliza em seus textos, constituindo, por conseguinte, uma manifestação de um ponto de vista do produtor do texto, que seleciona um conteúdo estereotipado para compor seu texto, marcando assim subjetivamente sua manifestação. Afinal, conforme ensina KerbratOrecchioni ([1980] 1997), as palavras da língua trazem sempre uma carga mais ou menos forte de subjetividade, pois elas servem para interpretar e representar o mundo. Lembramos, com Cabral (2011), que a subjetividade, desse ponto de vista, diz respeito ao fato de que manifestamos nosso posicionamento frente aos conteúdos que enunciamos, marcando subjetivamente nosso dizer, conforme realizamos nossas escolhas linguísticas.

Com respeito ao caráter subjetivo da linguagem e sua relação com estereótipo, podemos, pois, afirmar, com Cabral (2011), que ambos dizem respeito à forma como cada sujeito apreende e expressa a realidade que o cerca; afinal, somos seres sociais, marcados pela cultura em que vivemos e trazemos as crenças dessa cultura para nossos 
textos, marcando-os com nossas escolhas linguísticas. Esse processo de escolhas possibilita, segundo Kerbrat-Orecchioni ([1980]1997), dois tipos de construção: um discurso objetivo, que procura apagar qualquer traço da existência de um enunciador individual, ou um discurso subjetivo, no qual o produtor assume, explicitamente ou implicitamente, ser a fonte avaliadora do conteúdo do enunciado. O estudo da subjetividade da linguagem, desse ponto de vista, interessa-se pelos usos individuais do código comum, ou, conforme explica a autora, pela seleção de determinadas unidades no estoque lexical e sintático que lhe propõe o código para a composição de seus textos, marcando uma tomada de posição (KERBRAT-ORECCHIONI, [1980]1997).

Se as marcas de subjetividade permitem ao produtor situar-se perante os conteúdos enunciados, elas devem ser evitadas em determinados gêneros nos quais deve prevalecer a neutralidade, como é o caso das sentenças judiciais, conforme destacamos

na seção anterior deste trabalho. É preciso, no entanto, considerar o caráter gradual das marcas de subjetividade em um texto, conforme as unidades pertinentes sejam mais ou menos numerosas e densas (KERBRAT-ORECCHIONI, [1980] 1997). Isso quer dizer que mesmo um texto tendendo à neutralidade traz marcas que revelam a uma tomada de posição do produtor; essa tomada de posição se vale, muitas vezes, de estereótipos.

Relativamente ao papel argumentativo dos estereótipos, associando estes últimos à subjetividade, é importante destacar que as escolhas operadas pelo enunciador, na produção de um texto, têm a ver com suas intenções. $O$ fato é que, conforme ensina Ducrot (1984), construímos nossos enunciados, operando escolhas de acordo com nossas intenções e com base nas possibilidades que a língua nos oferece e nos limites que ela impõe. Essas escolhas são subjetivas e, muitas vezes, trazem avaliações fundadas em estereótipos, conforme veremos nas análises que apresentamos na próxima seção.

\section{Alguns estereótipos marcados na argumentação de uma sentença judicial}

O texto de análise a título de exemplificação constitui um acórdão proferido por uma câmara civil do Tribunal de Justiça do Estado do Rio de Janeiro em um recurso de apelação interposto contra a sentença de primeira instância, prolatada pelo juiz singular 
em uma ação civil de reconhecimento de união estável e de rateio de pensão previdenciária (TJRJ, 2016).

A ação tem como autora uma mulher que manteve relacionamento duradouro com um falecido servidor militar do Estado do Rio de Janeiro; em função desse relacionamento e do falecimento do militar, a autora pleiteou metade da pensão alegando que manteve com ele uma união estável por mais de 21 anos. São réus na ação a autarquia previdenciária estadual do Rio de Janeiro, Fundo Único de Previdência Social do Estado do Rio de Janeiro - RIOPREVIDÊNCIA, e a esposa do servidor falecido servidor.

Segundo consta na decisão objeto deste trabalho, quando o militar ainda era vivo, a autora já havia apresentado esse pleito no âmbito administrativo e obteve êxito na sua pretensão com a instituição da pensão em seu favor, mas tal benefício foi cancelado em razão de requerimento formulado pela segunda ré, a esposa com quem o falecido servidor ainda era casado oficialmente na ocasião de sua morte.

A ação objeto da sentença em análise foi julgada improcedente em primeira instância. O juiz motivou sua decisão com o principal argumento de que não havia elementos de prova suficientes para comprovar "a configuração de união estável entre a demandante e o finado Paulo, que era casado, mas mero relacionamento amoroso extraconjugal". A autora, entretanto, interpôs recurso, pretendendo o reconhecimento da união estável e a divisão do pensionamento pós morte do servidor falecido.

Cumpre esclarecer que, embora haja julgamentos monocráticos em segunda instância, normalmente eles são coletivos; a regra nas decisões terminativas que apreciam os recursos é o julgamento por órgãos colegiados denominados câmaras ou turmas, ou ainda por órgãos especiais ou o próprio pleno, dependendo do tribunal, conforme a organização judiciária. Nos julgamentos por órgãos colegiados, caso do texto em análise, sorteia-se um relator que elabora o seu voto e, se tal voto for vencedor, os demais membros apenas seguem aquela decisão, como se deu no julgamento do caso que analisamos neste trabalho.

Em seu voto, o relator segue o mesmo padrão das demais decisões judiciais, com a diferença de que, por ser tratar de uma decisão definitiva, seu desenvolvimento é mais pormenorizado, apontando todos os detalhes das ocorrências do processo. O relator, em primeiro lugar, identifica a ação, especifica quais fatos foram narrados, informa o pleito 
que foi formulado, a audiência realizada, a sentença que foi proferida em primeira instância e o recurso de apelação interposto, inclusive o resumo das alegações e argumentos elaborados pela apelante, ou seja, aquela que recorreu, e os apelados, ou seja, as outras partes que venceram a ação na primeira instância. Em seguida ao relatório, o julgador passa a fundamentar a decisão com os argumentos que entende suficientes para dar suporte à sua escolha por uma das teses em debate e, na decisão em análise, a não alteração da decisão de primeira instância.

Em seu texto, o relator delimita como questões controvertidas, em primeiro lugar, o direito da apelante a receber ou não a pensão, mediante a verificação das condições existentes no momento do óbito do ex-servidor. Apresenta a legislação que, na época, previa a possibilidade de pensionamento da companheira do associado pela autarquia previdenciária; avalia a comprovação da convivência pública e contínua, estabelecida com o objetivo de constituir família.

Tendo estabelecido os parâmetros para seu raciocínio, o relator passa a tecer os seus argumentos e a esclarecer quais valores toma como referência para chegar às conclusões a respeito da causa, tanto na motivação das escolhas que faz, como nas justificativas para tornar tais escolhas aceitáveis; finalmente, nega provimento ao recurso de apelação, sendo seguido pelos seus pares, os outros dois julgadores, resultando em decisão unânime contra o pedido da Autora.

É possível verificar, nos argumentos e valores postos pelo julgador, a presença de estereótipos tanto de caráter negativo, como de caráter positivo. Os estereótipos de caráter negativo são, evidentemente, associados à apelante, a quem se intenciona negar o pedido. Podemos assim identificar o estereótipo social da concubina, da amante e dos fatos que conduzem a eles, ou seja, o concubinato e o relacionamento ilegítimo. Em contrapartida a esse conjunto de estereótipos negativos, encontramos o relacionamento oposto ao concubinato e de caráter avaliativo positivo; trata-se do estereótipo da família, relacionamento reconhecido pela lei e socialmente aceito:

(1) Todavia, o relacionamento amoroso havido entre o servidor falecido e a ora apelante não era legítimo, pois não estava ele separado de fato de sua esposa, com quem era casado civilmente e com quem havia constituído família. (grifos nossos)

(2) Com efeito, o relacionamento amoroso extraconjugal não pode ser considerado público e contínuo, embora duradouro, vez que [sic] a relação concubinária é 
impeditiva ao reconhecimento da existência de legítima entidade familiar. (grifos nossos)

A concubina, ou amante, é a mulher considerada como aquela que mantém relacionamento ilegítimo com homem casado. Amante é aquela com quem o homem casado mantém um relacionamento sexual afetivo extraconjugal, com quem "dorme durante alguns dias da semana, mas sem pretender com ela construir "laços familiares", conforme mencionou o julgador no excerto que reproduzimos a seguir. O excerto que segue corrobora uma avaliação positiva para a família e o estereótipo de amante, conferindo-lhe avaliação negativa:

(3) Ademais, o simples fato de os amantes dormirem sob o mesmo teto, em alguns dias na semana, não é suficiente para caracterizar união estável, diante da inequívoca ausência de intenção deles em construir os laços familiares. (grifos nossos)

Também encontramos o estereótipo do companheiro em contraposição a seu "estado civil", deixando implícito que ela tinha conhecimento de que ele era casado e, inclusive, tinha um filho, fruto de seu casamento. Em (4), ao mencionar que a apelante tinha ciência de que o companheiro era casado, novamente o juiz polariza as duas posições, a da família constituída e a da amante. Podemos afirmar que o juiz, ao nomear o militar de "companheiro" da apelante, expressa sua crença de que o relacionamento existente entre eles não representava laço familiar, ou união estável.

(4) A apelante sabia do estado civil do então companheiro e, possivelmente, da existência de um filho proveniente daquela união.

Cumpre observar que o juiz demonstra preocupação em atenuar seu posicionamento contrário ao relacionamento extraconjugal para o qual a apelante busca reconhecimento como união estável, mostrando que não desconhece o modelo familiar sócio afetivo, reconhecido por lei, lembrando que a doutrina recepciona a existência de mais de uma entidade familiar:

(5) Não desconheço a questão acerca da simultaneidade de entidades familiares, que vem sendo tratada, pela doutrina que se posiciona pela sua admissibilidade, enfaticamente no sentido de que a proteção ao instituto do casamento não está no topo da hierarquia das entidades familiares, podendo haver, após a análise do caso concreto, o reconhecimento de mais de uma entidade familiar, a ensejar a proteção estatal. 
No exemplo (5), podemos verificar que, embora admitindo a existência, ao afirmar que não desconhece, não se pode afirmar que, em suas crenças, o juiz concorda com essa norma legal. Identificamos que ele mantem certo distanciamento em relação ao tema. Ele, por exemplo, em vez de dizer que tem conhecimento do assunto, limita-se a afirmar que "não desconhece". Apesar de utilizar a primeira pessoa, o emprego da negação, mesmo que com sentido de afirmação, mantém certo afastamento do conteúdo enunciado. Além disso, as demais formas verbais no excerto estão todas na terceira pessoa e as ações expressas pelo verbo são atribuídas a entidades abstratas. Assim, por exemplo, é a doutrina que determina a admissibilidade de outras formas de entidade familiar. O juiz mantem-se, dessa forma, distante de um posicionamento perante a questão.

A decisão apela à norma legal para citar os argumentos da publicidade e da continuidade para corroborar o estereótipo do casamento e, consequentemente, da esposa como elemento da família, e, portanto, de relacionamento aprovado socialmente e legalmente. Esses argumentos anulam o da durabilidade quando este é associado ao estereótipo da concubina, elemento de relacionamento não admissível, o extraconjugal:

(6) Com efeito, o relacionamento amoroso extraconjugal não pode ser considerado público e contínuo, embora duradouro...

Em suma, podemos observar que o juiz traz para a sua argumentação estereótipos de valor negativo, como a concubina e a amante, imputados à apelante e, relacionados a eles, relacionamento ilegítimo, o concubinato adulterino. Apresenta, por outro lado, estereótipos de valor positivo, como o do casamento legal e, a ele ligado, a família e a esposa, a ré/apelada. Prevalecem os estereótipos de valor positivo, refletindo a visão predominante na sociedade.

\section{Considerações finais}

As breves análises de excertos de uma sentença judicial nos permitem observar que o juiz, no processo decisório, deve escolher uma, ou algumas entre as alternativas que foram postas no processo. Essa escolha se dá mediante o conhecimento, a análise e a síntese dos argumentos produzidos nos autos pelas partes envolvidas. Dessa forma, o juiz desenvolve ele mesmo suas teses com a finalidade de chegar a uma conclusão, que 
exporá na decisão. Na fundamentação de sua decisão, o julgador apresenta os argumentos que dão suporte à decisão e façam com que ela seja dotada de sentido para aqueles que participam do processo e para os seus pares. Para tanto, não basta que se apresentem os elementos próprios da técnica jurídica; é importante que estejam presentes, na argumentação do julgador, elementos que enquadrem sua decisão em um contexto sociocultural no qual ela se mostre pertinente e com cujos valores ela seja coerente. Nesse contexto, torna-se admissível que o juiz, ser social, participante da sociedade para a qual ele exerce papel de julgador, manifeste suas crenças pessoais condizentes com os valores da sociedade em que se insere.

Podemos afirmar que, se de um lado, com o princípio secundum conscientizam, os juízes seguem sua consciência, transformando a ação de julgar num ato mais subjetivo; de outro, ele está submetido às crenças da sociedade em que vive e aos estereótipos sedimentados nessa sociedade e que ele toma para si, incorporando-os, construindo com eles suas próprias crenças. As motivações expostas em seus julgamentos refletem a existência desses estereótipos, que se marcam na sua linguagem na medida em que nos permite identificar uma visão de mundo, uma tomada de posição frente aos fatos, subjetivamente marcada, enfim.

\section{REFERÊNCIAS}

AL KARJOUSLI, Soufian. L'effacement de la polysémie dans la langue arabe: les couleurs dans le Coran comme base de stéreotypage. IN. Boyer, H. (dir.). Stéréotypages, stéréotypes : fonctionnements ordinaires et mises en scène. Tome 4 Langue(s), discours. Paris : L'Harmattan, 2007, p. 15 - 25.

AMOSSY, Ruth; PIERROT, Anne Herschberg. Stéréotypes et clichés. Paris: Armand Colin, [1997] 2007.

BOYER, Henri. Le stéréotypage ambivalent comme indicateur de conflit diglossique. IN. Boyer, H. (dir.). Stéréotypages, stéréotypes : fonctionnements ordinaires et mises en scène. Tome 4 Langue(s), discours. Paris : L'Harmattan, 2007, p. 39 - 47.

BRASIL. Código de processo civil: Lei n.13.105, de março de 2015. Brasília: Senado Federal, Secretaria de Editoração e Publicações. 2015. Disponível em: <http://www2.senado.gov.br/bdsf/handle/id/507525>. Acesso em: 19 ago. 2016.

BRASIL. Constituição (1988). Constituição da República Federativa do Brasil. Promulgada em 05 de outubro de 1988. Disponível em: 〈http://www.planalto.gov.br/ccivil_03/Constituicao/Constituicao.htm>. Acesso em 19 ago. 2016. 
CABRAL, Ana Lúcia Tinoco. Enunciação e escrita acadêmica na área jurídica: subjetividade, intersubjetividade e argumentação. In: Sparano, Magalí; Vargas, Maria Valíria A. M. Enunciação, subjetividade e práticas de linguagem: revisitando Benveniste. São Paulo: Paulistana, 2011, p 92-110.

Negação, intersubjetividade e polifonia: estudo de caso em processos civis. Revista Letras de Hoje, Vol. 51, n. 1. (2016), p 55-64.

Disponível

em <ttp://revistaseletronicas.pucrs.br/fo/ojs/index.php/fale/article/view/21556/14337>, acesso em 12/03/2017.

Enunciação e Argumentação no Discurso Jurídico: léxico, significação e sentido. In: Oliveira, E. G. de; Silva, S. (org.) Semântica e Estilística: dimensões atuais do Significado e do Estilo. Homenagem a Nilce Santa'anna Martins. Campinas: Pontes Editores, 2014, p. 57-73.

A Interação Verbal em Processos Civis: um caso de trílogo. In: GIL, B. D.; AQUINO, Z. G. O. Anais do II Simpósio Internacional de Análise Crítica do Discurso e VIII Encontro Nacional de Interação em Linguagem Verbal e Não Verbal. Faculdade de Filosofia, Letras e Ciências Humanas, USP, 2007. Disponível em

http://www.fflch.usp.br/dlcv/enil/pdf/76_Ana_Lucia_TC.pdf, acesso em 13/02/2017.

CHARAUDEAU, Patrick. Les stéréotypes, c'est bien, les imaginaires, c'est mieux. IN. Boyer, H. (dir.). Stéréotypages, stéréotypes : fonctionnements ordinaires et mises en scène. Tome 4 Langue(s), discours. Paris : L'Harmattan, 2007, p. 49 - 63.

CINTRA, Antonio Carlos Araujo; GRINOVER, Ada Pelegrini; DINAMARCO, Cândido Rangel. Teoria Geral do Processo; $28^{a}$ ed. São Paulo: Malheiros, 2012.

DINAMARCO, Cândido Rangel. Instituições de Direito Processual Civil. 7.ed. v.1. São Paulo: Malheiros, 2013.

DUCROT, Oswald. Le dire et le dit. Paris: Minuit, 1984.

KERBRAT-ORECCHIONI, Catherine. L'énonciation. Paris: Armand Colin, [1980] 1997.

RHEAULT, Amélie-Hélène. L'utilisation des stéréotypes et des lieux communs dans le discours épilinguistique: vers une approche argumentative des représentations linguistiques. IN. Boyer, H. (dir.). Stéréotypages, stéréotypes : fonctionnements ordinaires et mises en scène. Tome 4 Langue(s), discours. Paris : L'Harmattan, 2007, p. $175-182$.

TJRJ. Tribunal de Justiça do Estado do Rio de Janeiro. Apelação cível n. ${ }^{\circ} 0069578$ 62.2011.8.19.0001. Relator Desembargador Benedicto Abicair. 2016. Disponível em $<$ http://www1.tjrj.jus.br/gedcacheweb/default.aspx?UZIP=1\&GEDID=0004132BBEE8 E62D108E7ACBE63903029C92C5044A4F4457>, acesso em 10/10/2016. 
THEODORO JUNIOR, Humberto. Curso de direito processual civil - Teoria geral do direito processual civil e processo de conhecimento. Rio se Janeiro: Forense, 2007. 